\title{
Indications for the role of the immune system in the pathogenesis of corneal alkali burns
}

\author{
YITSHAK BEN HANAN, NAHUM LANDSHMAN, ISAAC AVNI, \\ ABRAHAM KARSIK, AND MICHAEL BELKIN \\ From the Maurice and Gabriela Goldschleger Eye Research Institute, Tel-Aviv University, Israel
}

SUMmaRY We produced alkali burns $(1.5 \mathrm{~N} \mathrm{NaOH})$ in the right eyes of 63 mice. Three weeks later the left eye of each mouse was similarly burned. All eyes were followed up weekly for 4 weeks after the burn and were graded according to the severity of the lesion. The lesions developed much faster and were more severe in the left eyes. These results suggest that the body's immune mechanism participates in the pathogenesis of alkali corneal burns and adversely affects the development of this condition.

The immunological aspects of chemical burns have received scant attention in ophthalmic research, and the subject is hardly mentioned in the literature. There are some indications that the immune system is intimately involved with the development of the delayed effects of burns. It is known that burns are not a local phenomenon only and that the burned area is a source of antigens. ${ }^{12}$ These antigens are mostly autoantigens resulting from alterations in the body's own proteins and from unaltered antigens coming in contact with the immune system for the first time.$^{3-6}$ These antigens cause an immune response which participates in the healing of the burns. ${ }^{7 \rightarrow}$ The autoantibodies produced can cause severe systemic disease when they enter the circulation. Treatment with burns convalescence serum is reported to

Correspondence to Professor Michael Belkin, Maurice and Gabriela Goldschleger Eye Research Institute, Tel-Aviv University Sackler School of Medicine, Tel Hashomer, 5261, Israel. improve considerably the survival of burned experimental animals. ${ }^{10}$

Evidence for the participation of the body's immune system in the pathogenesis of 'burn disease' of the eye is even more vague, circumstantial, and indirect. Ulceration, thinning, and melting of the cornea occur in severe cases 2 to 3 weeks after the injury. ${ }^{112}$ This period coincides not only with the peak of collagenase activity ${ }^{13}$ but also with possible humoral immune reaction, the 2 processes being possibly interrelated. The period of about 3 weeks after the injury is also associated with a tendency for inflammatory cells, including lymphocytes, to infiltrate the cornea and iris. ${ }^{1415}$ The occurrence of uveitis for a prolonged time after the burn ${ }^{16}$ may also indicate that an immune mechanism is involved in the process. Another strong indicator of the involvement of the immune system in ocular burns is the presence of physiological and metabolical effects of uniocular burns in the fellow eye. ${ }^{17}$

Table 1 Number and percentage of eyes graded into each scale category at the weekly examination. Details of the gradation are given in the text

\begin{tabular}{|c|c|c|c|c|c|c|c|c|c|c|c|c|}
\hline \multirow{3}{*}{$\begin{array}{c}\text { Days } \\
\text { after } \\
\text { burn } \\
\qquad\end{array}$} & \multicolumn{4}{|c|}{ Mild } & \multicolumn{4}{|c|}{ Moderate } & \multicolumn{4}{|c|}{ Severe } \\
\hline & \multicolumn{2}{|c|}{ First eye } & \multicolumn{2}{|c|}{ Second eye } & \multicolumn{2}{|c|}{ First eye } & \multicolumn{2}{|c|}{ Second eye } & \multicolumn{2}{|c|}{ First eye } & \multicolumn{2}{|c|}{ Second eye } \\
\hline & $N$ & $\%$ & $N$ & $\%$ & $N$ & $\%$ & $N$ & $\%$ & $N$ & $\%$ & $N$ & $\%$ \\
\hline 7 & 4 & $6 \cdot 3$ & 1 & 1.8 & 39 & $61 \cdot 9$ & 32 & $57 \cdot 1$ & 16 & $25 \cdot 4$ & 22 & $39 \cdot 3$ \\
\hline 14 & - & - & - & - & 5 & $8 \cdot 3$ & 1 & 1.9 & 42 & $70 \cdot 0$ & 17 & 32.0 \\
\hline 21 & 1 & 1.8 & - & - & 31 & 54.4 & 6 & 11.8 & 15 & $26 \cdot 3$ & 24 & $47 \cdot 0$ \\
\hline 28 & 17 & $30 \cdot 4$ & 1 & $2 \cdot 0$ & 17 & $30 \cdot 4$ & 17 & $34 \cdot 0$ & 12 & $21 \cdot 4$ & 3 & 6.0 \\
\hline
\end{tabular}


To determine whether the immune system has a role in the pathogenesis of alkali burns we investigated the rate of development of the effects of burns in the eyes of mice when one eye was burned 3 weeks after the fellow eye.

\section{Material and methods}

An alkali burn was produced in the right eye of each of 63 ether anaesthetised black inbred (strain C-56) male mice. The burn was produced by prolapsing the eye and inserting it into a cup of $4 \mathrm{~mm}$ diameter filled with $1.5 \mathrm{~N} \mathrm{NaOH}$. After 10 seconds in the $\mathrm{NaOH}$ solution the eye was inserted into a larger cup filled with saline for 10 seconds. Each animal was biomicroscopically examined weekly for one month.

The state of the eye was graded according to the following scale: (1) mild-superficial corneal erosion, iris clearly visible; (2) moderately severe-deeper corneal erosion, iris not visible; (3) severe-deep corneal ulcer or descematocele; (4) perforation of the cornea: (5) healing (following erosion, ulcer, or perforation) with epithelisation and neovascularisation. The cases of phthisis bulbi were included in this category.

Three weeks after the production of the burn in the right eye an identical burn was made in the left eye of the surviving 56 mice. These eyes were examined and graded similarly to the right eyes.

\section{Results}

The condition of the eyes burned first and the eyes burned 3 weeks later at the weekly examinations are given in Table 1. It is clear that the lesions of the eyes which were burned 3 weeks after their fellow eyes developed at a faster rate than the lesions in the first eyes. After 2 weeks $66 \%$ of the second eyes perforated while only $21.7 \%$ of the first eyes perforated. The respective numbers for the third week was $39.2 \%$ and $17.5 \%$. The lesions in the second eyes tended to be more severe: less than half of the first eyes perforated, while almost all the second eyes reached that stage within a month.
The distribution of the eyes between the 4 grades of severity at each examination was statistically evaluated by the $\chi^{2}$ test $(2 \times 3$ contingency tables). It was found that the second eyes were significantly $(p<0.001)$ more affected at all examinations except at the first week's examination.

\section{Discussion}

Our results show that the rate of development and the final severity of the lesions were significantly more serious in eyes which were subjected to alkali burns 3 weeks after their fellow eyes were similarly burned. These results suggest that the body's immune mechanism is involved in the pathogenesis of the alkali burn lesion. A possible mechanism is the formation of new antigens by the action of the alkali in the cornea. The antigens, liberated into the circulation, may induce the appearance of humoral antibodies. These antibodies react with their specific antigens created in the eye burned subsequently and aggravate its condition. Alternatively or concurrently the chemical burn may cause the release into the circulation of antigens which are not normally present there. The antibodies which are consequently induced affect the second eye similarly burned. The suggestion that the immune system participates in the pathogenesis of alkali burns requires further proof.

We are now investigating the effect of immunosuppressants on the development of the lesions in second eyes. Negation of the accelerated development of the lesion in these eyes will prove participation of the immune system. The exact mechanisms will then have to be determined.

\section{References}

1 Grever W. Zur Pathophysiologie und Therapie der Verbrenungkrankheit. Bruns Beitr Klin Chir 1959; 3: 198.

2 Shilov PL, Pilushin PV. Internal pathology in burns. Moscow: Medgiz, 1962.

3 Federov NA, Koryakina IK, Podoprigora GI. Study on the nature of toxic factors in burns in conditions of gnotobiotic experiment (gnotobiological). Biull Eksp Biol Med 1973; 76: 17-19.

\begin{tabular}{|c|c|c|c|c|c|c|c|c|c|c|c|}
\hline \multicolumn{4}{|c|}{ Perforation } & \multicolumn{4}{|c|}{ Healing } & \multicolumn{4}{|c|}{ Total } \\
\hline \multicolumn{2}{|c|}{ First eye } & \multicolumn{2}{|c|}{ Second eye } & \multicolumn{2}{|c|}{ First eye } & \multicolumn{2}{|c|}{ Second eye } & \multicolumn{2}{|c|}{ First eye } & \multicolumn{2}{|c|}{ Second eye } \\
\hline$N$ & $\%$ & $N$ & $\%$ & $N$ & $\%$ & $N$ & $\%$ & $N$ & $\%$ & $N$ & $\%$ \\
\hline 4 & $6 \cdot 3$ & 1 & 1.8 & - & - & - & - & 63 & 99.9 & 56 & 100 \\
\hline 13 & $21 \cdot 7$ & 35 & $66 \cdot 0$ & - & - & - & - & 60 & 100 & 53 & 99.9 \\
\hline 10 & 17.5 & 20 & $39 \cdot 2$ & - & - & 1 & $2 \cdot 0$ & 57 & 100 & 51 & 100 \\
\hline- & - & 3 & $6 \cdot 0$ & 10 & $17 \cdot 9$ & 26 & $52 \cdot 0$ & 56 & 100 & 50 & 100 \\
\hline
\end{tabular}


4 Kuznetzova NI, Skurkovich SR. Auto-antibodies in burns. Pat Fiziol Eksp Ter 1959; 3: 57-60.

5 Kolker II, Kaem RI, Vul SM. Infections and immunologic aspects of burn disease. Arch Pathol 1974; 36: 3-13.

6 Koryakina IK, Zajets TL, Nikulin VI. Nature of the toxicity of rat serums and organs following thermal burns. Biull Eksp Biol Med 1973; 76: 17-9.

7 Engelhardt GH, Struck H. Antibody production in burns. Res Exp Med (Berl) 1972; 7: 186-8.

8 Fischer H. Immunological problems in burns. Hippokrates 1976; 47: 387-9.

9 Kolker II Autoimmune processes in burns disease. Pat Fiziol Eksp Ter 1969; 13: 78-84.

10 Federov NA, Skurkovich SV, Freiman VT, Muzichenko AP. Experimental investigation on burn autoantigens. Pat Fiziol Exp Ter 1959; 3: 53-8.
11 Hughes WF. Alkali burns of the eye: I Review of the literature and summary of present knowledge. Arch Ophthalmol 1946; 35: 423-9.

12 Pfister RR, Friend J, Dohlman CK. The anterior segment of rabbits after alkali burns. Arch Ophthalmol 1969; 82: 91-4.

13 Anderson RE, Kuns MD, Dresden MH. Collagenase activity in the alkali burned cornea. Ann Ophthalmol 1971; 3: 619-21.

14 Hughes WF. Alkali burns of the eye: II Clinical and pathological course. Arch Ophthalmol 1946; 36: 189-214.

15 François J, Feher J. Collagenolysis and regeneration in corneal burnings. Ophthalmologica 1972; 165: 137-52.

16 Girard LJ, Alford WE, Feldman GL, Williams B. Severe alkali burns. Trans Am Acad Ophthalmol Otolaryngol 1970; 74: 788-803.

17 Obenberger J, Babicky A. Alkali burns of the rabbit cornea. Ophthalmic Res 1975; 5: 1-9. 